\title{
Role of habitat complexity in predator-prey dynamics between an introduced fish and larval Long-toed Salamanders (Ambystoma macrodactylum)
}

\author{
Authors: Erin K. Kenison, Andrea R. Litt, David S. \\ Pilliod, and Tom E. McMahon
}

This is a postprint of an article that originally appeared in Canadian Journal of Zoologv on April 2016 at https://dx.doi.org/10.1139/ciz-2015-0160.

Kenison, Erin K. , Andrea R. Litt, David S. Pilliod, and Tom E. McMahon. "Role of habitat complexity in predator-prey dynamics between an introduced fish and larval Long-toed Salamanders (Ambystoma macrodactylum)." Canadian Journal of Zoology 94, no. 4 (April 2016): 243-249. DOI: 10.1139/cjz-2015-0160.

Made available through Montana State University's $\underline{\text { ScholarWorks }}$ scholarworks.montana.edu 


\title{
Role of habitat complexity in predator-prey dynamics between an introduced fish and larval Long-toed Salamanders (Ambystoma macrodactylum)
}

\author{
Erin K. Kenison, Andrea R. Litt, David S. Pilliod, and Tom E. McMahon
}

\begin{abstract}
Predation by nonnative fishes has reduced abundance and increased extinction risk for amphibian populations worldwide. Although rare, fish and palatable amphibians have been observed to coexist where aquatic vegetation and structural complexity provide suitable refugia. We examined whether larval Long-toed Salamanders (Ambystoma macrodactylum Baird, 1850) increased use of vegetation cover in lakes with trout and whether adding vegetation structure could reduce predation risk and nonconsumptive effects (NCEs), such as reductions in body size and delayed metamorphosis. We compared use of vegetation cover by larval salamanders in lakes with and without trout and conducted a field experiment to investigate the influence of added vegetation structure on salamander body morphology and life history. The probability of catching salamanders in traps in lakes with trout was positively correlated with the proportion of submerged vegetation and surface cover. Growth rates of salamanders in enclosures with trout cues decreased as much as $85 \%$ and the probability of metamorphosis decreased by $56 \%$. We did not find evidence that adding vegetation reduced NCEs in experimental enclosures, but salamanders in lakes with trout used more highly vegetated areas, which suggests that adding vegetation structure at the scale of the whole lake may facilitate coexistence between salamanders and introduced trout.
\end{abstract}

Key words: Long-toed Salamander, Ambystoma macrodactylum, experimental enclosures, refuge use, predator cues, submerged vegetation, growth rate.

\section{Introduction}

Refugia are crucial for allowing prey to persist with predators; complex vegetation structure reduces the maneuverability, visual range, and effectiveness of predators (Werner et al. 1983; McNair 1986; Sih 1987; Kats et al. 1988; Sih et al. 1988). Predator and prey populations can oscillate in an unstable manner over time, depending on the efficiency of a predator at capturing and consuming prey (Rosenzweig and MacArthur 1963). However, increases in habitat complexity reduce the frequency and success of predator attacks on prey and therefore can stabilize species interactions
(Murdoch and Oaten 1975; Sih 1987; Diehl 1992). Refugia provide protection from predators, increase food resources for prey, reduce physical stress and competition among individuals, and subsequently, enhance prey density and stable species interactions (Crowder and Cooper 1982; Sih 1987; O'Connor 1991; Diehl 1992).

Trout, salmon, and char (family Salmonidae) have been introduced for recreational and commercial purposes worldwide, including historically fishless waters, resulting in considerable ecological effects on native species and ecosystems (Dunham et al. 2004; Crawford and Muir 2008; Cucherousset and Olden 2011). The introduction of these top predators has resulted in decreases in 
abundance and extirpations of amphibian populations (Kats and Ferrer 2003; Pilliod et al. 2012). The Long-toed Salamander (Ambystoma macrodactylum Baird, 1850), one of the most widely distributed amphibians west of the Continental Divide, is especially vulnerable to nonnative, introduced fish. This salamander is palatable, lacks chemical defenses, and has an extended larval period (1-3 years), during which larvae must overwinter in deep, ice-free lakes often alongside predatory fish (Welsh et al. 2006; Pilliod et al. 2010). In lakes with trout, the abundance of salamander egg masses is lower, larvae are $>65 \%$ less abundant, and some populations have been extirpated (Tyler et al. 1998a; Funk and Dunlap 1999; Pilliod and Peterson 2001; Bull and Marx 2002; Welsh et al. 2006; Hirner and Cox 2007; Pearson and Goater 2008; Pilliod et al. 2010).

The few lakes where salamanders and trout have been found to co-occur (i.e., existing in the same lake together) have emergent vegetation and shallow littoral zones that likely provide adequate refugia from fish predators (Tyler et al. 1998a; Pearson and Goater 2008; Pilliod et al. 2010, 2013). Salamanders are capable of detecting predator cues and respond by increasing refuge use to avoid predation, but incur concomitant reductions in energy uptake (Semlitsch 1987; Figiel and Semlitsch 1990; Skelly and Werner 1990; Tyler et al. 1998b; Kenison et al. 2016). Salamanders that co-occur with trout exhibit a number of nonconsumptive effects (NCEs; Davenport et al. 2014), including reduction in size and growth and delayed metamorphosis, which are induced by the presence of trout or their cues alone (Kenison et al. 2016). Such strong effects on body morphology and life history in the presence of trout are likely to have significant effects on predation risk and reproductive success (Semlitsch 1987).

The objectives of our study were to (i) examine refuge use by larval Long-toed Salamanders in lakes with and without trout and (ii) test whether the addition of complex vegetation structure can reduce the NCEs of trout on salamander larvae and thereby facilitate persistence of salamanders in lakes where nonnative trout are present. We predicted that salamanders in lakes with trout would be found in denser cover compared with lakes without trout. We also predicted that individuals would be smaller and less likely to metamorphose in enclosures with trout cues than in enclosures without trout cues, but that added vegetation structure would reduce these NCEs, such that salamanders in enclosures with and without trout cues would be comparable in size. Our study is the first to experimentally supplement available refugia in an attempt to reduce NCEs of predatory trout on salamanders and provide a more feasible management strategy to trout removal.

\section{Materials and methods}

\section{Salamander refuge use}

We compared refuge use of Long-toed Salamanders in 14 permanent lakes, 7 lakes with trout and 7 lakes without trout, in the Flathead National Forest between the Swan and the Mission Mountain ranges in northwestern Montana during the summer of 2012 (Kenison et al. 2016). Trout species in our study lakes included rainbow trout (Oncorhynchus mykiss (Walbaum, 1792)), cutthroat trout (Oncorhynchus clarkii (Richardson, 1836)), or hybrids of the two; we were unable to determine the density of fish in each study lake due to time constraints and equipment limitations. We captured salamander larvae with mesh, collapsible minnow traps $(0.25 \mathrm{~m}$ long $\times 0.25 \mathrm{~m}$ wide $\times 0.43 \mathrm{~m}$ high), which are associated with little mortality or injury and are effective at capturing salamanders passively without bait (Adams et al. 1997). We set all traps in the littoral zone around the perimeter of each lake at depths $\leq 1 \mathrm{~m}$. The total number of traps in each lake depended on lake size and ranged from 6 to 16 ; lake perimeters ranged between 110 and $960 \mathrm{~m}$. We deployed traps in the same locations in each lake for four, 4-day trapping sessions from July through August 2012.
We quantified submerged vegetation and surface cover at every other trap location in all study lakes during each of the four trapping sessions as measures of habitat complexity or refugia. We quantified the proportion of submerged vegetation by resting a $1 \mathrm{~m}$ long chain, composed of 44 links, each $2.3 \mathrm{~cm}$ long, along the lake bottom at every other trap location. We counted the number of chain links in contact with vegetation under the water (i.e., living material such as stems) and converted counts of chain links into proportion of submerged vegetation (Kinsolving and Bain 1990). We also estimated the proportion of emergent vegetation on the water surface (i.e., surface cover) within a $1 \mathrm{~m}^{2}$ quadrat above every other trap location. We measured habitat characteristics at every other trap location rather than every location because this design allowed us a reasonable, yet more feasible measure of habitat along the entire lake perimeter.

\section{Enclosure experiment}

In 2013, we conducted a field experiment in 5 of the original 14 lakes, 2 lakes with trout and 3 lakes without trout, to investigate the effectiveness of adding vegetation structure to mitigate NCEs of trout on larval salamanders. The five study lakes selected had the highest densities of salamanders, which ensured that we had sufficient individuals for experiments without the need for between-lake transplants. We constructed experimental field enclosures with PVC pipe and fiberglass window screening $(2 \mathrm{~m}$ long $\times$ $1 \mathrm{~m}$ wide $\times 1 \mathrm{~m}$ high) (Sredl and Collins 1991; Kiesecker and Blaustein 1998). PVC pipes provided structure and support for the rectangular frame and screening was secured around the four sides and the bottom of the enclosure to allow continuous water exchange between enclosures and the lake. We covered the top of the enclosure with chicken wire to restrict avian predators. Experimental treatments were based on a $2 \times 2$ factorial arrangement: (i) presence or absence of trout cues (i.e., enclosures in lakes with trout compared with those without trout) and (ii) presence or absence of added vegetation structure. The trout treatments exposed larval salamanders to the chemical or visual signals of predators, but protected larvae from direct predation. This factorial design allowed us to test for the effects of refuge, the effects of trout cues, and the combined effects of trout cues and added vegetation.

We constructed complex vegetation structures by binding approximately 20 dead, dry sticks with 20 living, leafy branches (i.e., aspen or other littoral vegetation) with twine in an inverted funnel shape (Fig. 1; Schneider and Winemiller 2008). All vegetation was collected at study sites and not transported between lakes. Vegetation structures were roughly $50 \mathrm{~cm}$ in circumference at the base and $50-60 \mathrm{~cm}$ tall. We placed two vegetation structures in each enclosure that was assigned to added vegetation treatments, one structure at each end of the enclosure, and secured them in place with a large rock.

We placed enclosures in the littoral zone, along the northfacing edge of each lake to minimize potential differences among sites (e.g., temperature) within a lake. We positioned enclosures so that depth, distance between enclosures, and distance from shore were equal for all enclosures (Sredl and Collins 1991). We also added $\sim 10 \mathrm{~L}$ of lake substrate to the bottom of each enclosure to incorporate natural sediment. Lakes with trout had four replicates of each of the two possible treatments (presence of trout cues, with and without added vegetation structure) for a total of eight enclosures per lake. Lakes without trout had two replicates of each of the two possible treatments (absence of trout cues, with and without added vegetation structure) for a total of four enclosures per lake.

We captured salamanders with minnow traps and added individuals that were comparable in size ( $>0.2 \mathrm{~g}$ ) to experimental enclosures during June and July 2013. We anesthetized salamander larvae with MS-222, measured mass, snout-vent length (SVL), total length, tail length, and tail depth (height of the tail) with an electronic scale (to the nearest $0.001 \mathrm{~g}$ ) and calipers (to the nearest 
Fig. 1. Vegetation structure constructed for enclosures made with dead and living plant materials and secured with twine.

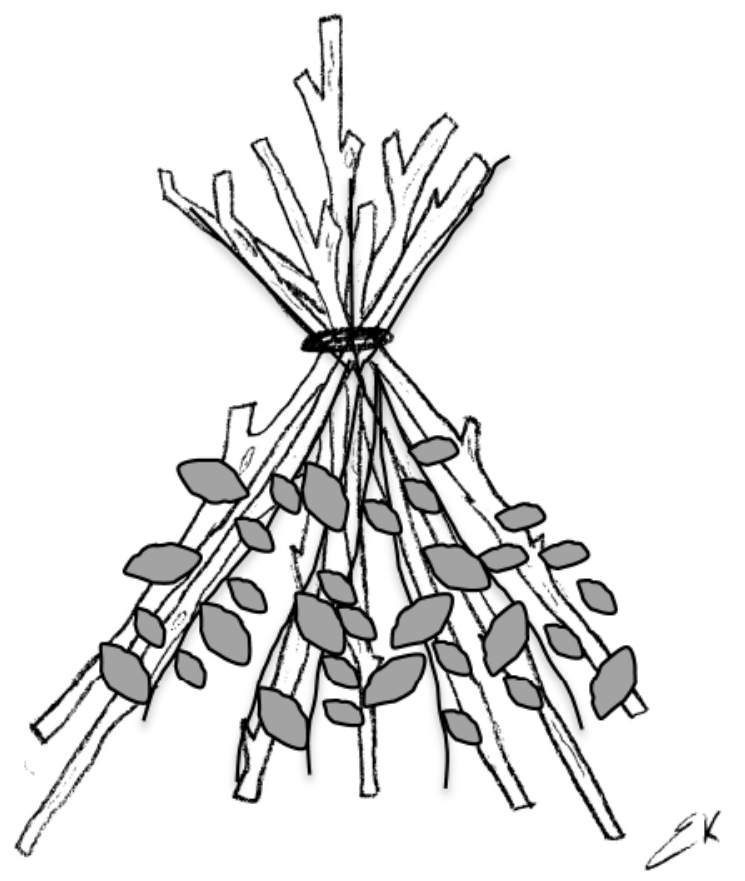

$0.1 \mathrm{~mm}$ ), and marked each individual using visual implant elastomer with a unique two-color mark in the middle of their tail. We randomly assigned 20 salamanders to each enclosure; salamander densities were comparable with previous studies that did not observe cannibalism and where adequate amounts of food persisted throughout the study periods (e.g., Clark 1986; Semlitsch 1987; Tyler et al. 1998b; Pearson and Goater 2009). Although we expected zooplankton and other small crustaceans to be able to pass through the enclosure screen, we added $\sim 10 \mathrm{~L}$ of lake water to enclosures at each visit to provide additional food resources (Stenhouse 1985; Tarr and Babbitt 2002).

After adding salamanders, we visited each enclosure four additional times during July and August 2013. At each enclosure visit, we captured individual larvae with hand nets and recorded measures of body morphology (i.e., mass, SVL, total length, tail length, and tail depth). We also noted whether salamanders had initiated metamorphosis, which we defined as any evidence of gill absorption (Dodd and Dodd 1976; Arntzen 1981; Duellman and Trueb 1986). After we completed data collection, we released individuals that had absorbed their gills completely into the lake and returned other individuals to assigned enclosures. We were unable to measure survival accurately, as we could not distinguish with certainty whether salamanders missing from enclosures escaped or died due to predation by invertebrates, conspecific cannibalism, or natural causes. At the end of the experimental period, salamander densities were comparable between enclosures in lakes with and without trout. We terminated the experiment at the end of August, released all remaining individuals in the lake, and removed enclosures. We anesthetized, marked, and handled all captured individuals in accordance with Montana State University Institutional Animal Care and Use Committee protocols 2012-28 and 2013-04.

\section{Statistical analyses}

We assessed refuge use by quantifying the relationship between the number of salamanders captured and the proportion of submerged vegetation and surface cover; we compared this relationship between lakes with and without trout. We assessed the importance of adding vegetation structures by comparing sala- mander growth rates, size of salamanders at metamorphosis, and the probability of metamorphosis across all four experimental treatments: (1) presence of trout cues (i.e., lakes with trout) and added structure, (2) presence of trout cues and no added structure, (3) absence of trout cues (i.e., lakes without trout) and added structure, and (4) absence of trout cues and no added structure. We used generalized linear mixed models with random slopes and intercepts for all of our analyses to account for repeated measurements in lakes and over time (Zuur et al. 2009).

To assess refuge use, we included the presence-absence of trout and vegetation measurements as main effects in our analytical models and also included the date of each trapping session to account for changes in vegetation abundance over time. We tested for interactive effects between presence-absence of trout and vegetation measurements, but removed interactions that did not explain sufficient variation $(P>0.1)$. We treated lakes as subjects and used a nested data structure that included individual traps nested within lakes, sampled over multiple visits, as our random effects. We excluded two lakes from these analyses because we did not capture any salamanders in traps where vegetation was measured.

To assess the importance of adding vegetation structures on the NCEs of trout in our enclosure experiment, we considered all measurements of body morphology (i.e., mass, SVL, total length, tail length, and tail depth) as separate response variables in our models. We included experimental treatments (i.e., presenceabsence of trout cues (trout) and presence-absence of vegetation structure (structure)) as main effects. We quantified growth rates and size at metamorphosis as a function of trout cues and vegetation structure by examining simple (trout, structure) and interactive effects (trout $\times$ structure). We also considered all possible two-way interactions between treatment factors and time (trout $x$ structure, trout $\times$ day, structure $\times$ day) in models for probability of metamorphosis, but removed interactions that did not explain sufficient variation $(P>0.1)$. We included a nested data structure that matched our design; we collected multiple measurements of salamanders within enclosures within the study lakes, sampled over time (day: modeled as the number of days since the first enclosure visit), as random effects.

We ran all statistical analyses in program $\mathrm{R}$ version 3.0.2 and used the nlme and MASS packages (R Core Team 2013). We report probability of salamander capture as a function of the proportion of submerged vegetation and surface cover. We estimate differences in growth rates, size at metamorphosis, and the probability of metamorphosis for salamanders in enclosures. We also provide 95\% confidence intervals (CI) for all estimates.

\section{Results}

\section{Salamander refuge use}

The probability of salamander capture was related to the proportion of submerged vegetation, but the magnitude and direction of this relationship depended on presence-absence of trout (Fig. 2A). In lakes with trout, salamanders were more likely to be captured in areas with more submerged vegetation, whereas this relationship reversed in the absence of trout (Fig. 2A). For each additional 0.1 increase in the proportion of submerged vegetation, the odds of capture increased by a factor of $1.25(95 \% \mathrm{CI}=$ 0.75-2.07) in lakes with trout or by a factor of $0.82(0.66-1.01)$ in lakes without trout $\left(t_{[465]}=2.86, P=0.004\right.$; Fig. $\left.2 A\right)$. We found some evidence that salamanders preferred areas with more vegetation cover at the water surface, but this relationship did not depend on the presence-absence of trout $\left(t_{[466]}=1.54, P=0.123\right.$; Fig. $\left.2 \mathrm{~B}\right)$. For every 0.1 increase in the proportion of surface cover, the odds of capture increased by a factor of 1.17 (0.65-1.44), regardless of whether trout were present. 
Fig. 2. Probability of capturing Long-toed Salamanders (Ambystoma macrodactylum) as a function of (A) the proportion of submerged vegetation and (B) the proportion of vegetation cover on the water surface ( $n=398$ salamanders in 67 traps) in northwestern Montana during the summer of 2012. Points are jittered to better distinguish salamander capture data.

A.

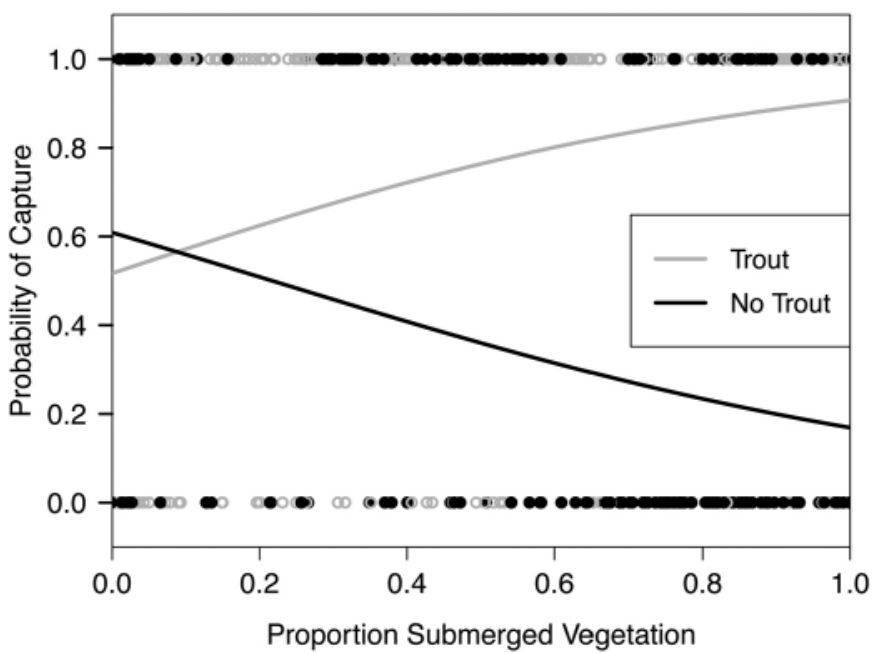

B.

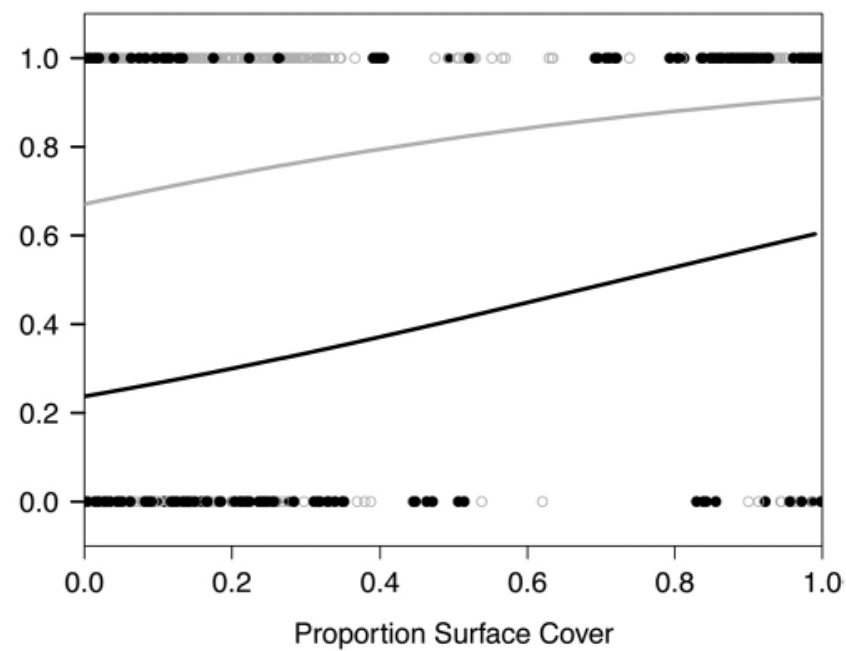

Fig. 3. Rates of growth per day (with 95\% CIs) for Long-toed Salamanders (Ambystoma macrodactylum) in enclosures without trout cues or structure (- trout, - structure; $n=120$ salamanders, 6 enclosures), without trout cues but with added structure (- trout, + structure;

$n=123$ salamanders, 6 enclosures), with trout cues but without structure (+ trout, - structure; $n=160$ salamanders, 8 enclosures), and with trout cues and added structure (+ trout, + structure; $n=160$ salamanders, 8 enclosures) in northwestern Montana during the summer of 2013.
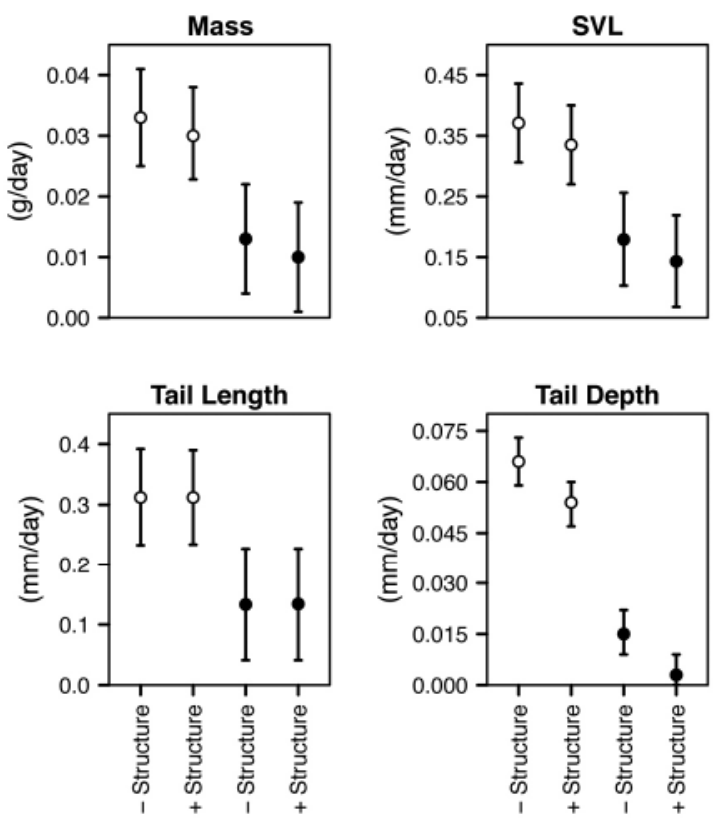

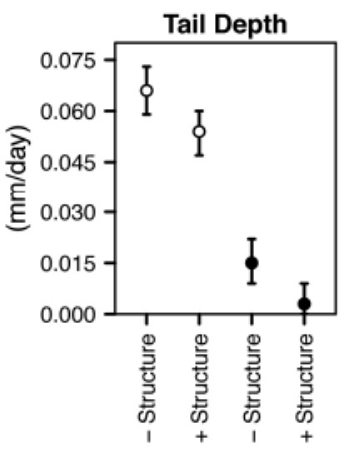

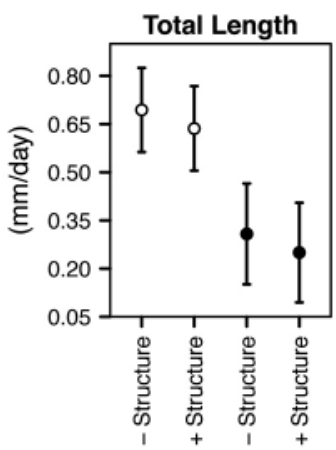

$$
\begin{array}{ll}
\circ & - \text { Trout } \\
\text { - } & + \text { Trout }
\end{array}
$$

\section{Enclosure experiment}

Adding vegetation structure to experimental field enclosures had no detectable effect on growth rates or body morphology of salamanders, but we found substantial differences among body measurements between enclosures with and without trout cues (Fig. 3, Table 1). Salamanders in enclosures without trout cues, on average, gained $64 \%$ more mass $(95 \% \mathrm{CI}=48 \%-90 \%$ ) and grew $54.5 \%$ more in SVL (43\%-70\%), 58\% more in total length (45\%-77\%), 57\% more in tail length (42\%-82\%), and $85 \%$ more in tail depth (77\%-92\%) per day compared with salamanders in enclosures with trout cues.

Body morphology at the time of metamorphosis was similar across all treatments (Table 2), but the probability of metamorphosing depended on presence-absence of trout. Salamanders ex- posed to trout cues had the lowest probability of metamorphosis throughout the experiment, compared with salamanders not exposed to trout cues, regardless of the presence of added vegetation structure (Fig. 4). On average, for each additional day, the odds that salamanders in enclosures without trout cues would metamorphose was $15 \%$ higher $(95 \% \mathrm{CI}=9 \%-23 \%)$ compared with the odds of salamanders metamorphosing in enclosures with trout cues, after accounting for vegetation treatment (Fig. $4 ; t_{[1916]}=-3.31, P=0.001$ ).

\section{Discussion}

In our study, the greater use of areas with more submerged vegetation by Long-toed Salamanders in lakes with trout supports 
Table 1. Factors affecting growth rate (change in size over time, denoted by "date") of Long-toed Salamanders (Ambystoma macrodactylum) in experimental enclosures without trout cues or structure (no trout, no structure; $n=120$ salamanders, 6 enclosures), without trout cues but with added structure (no trout, added structure; $n=123$ salamanders, 6 enclosures), with trout cues but without structure (trout, no structure; $n=$ 160 salamanders, 8 enclosures), and with trout cues and added structure (trout, added structure; $n=160$ salamanders, 8 enclosures) in northwestern Montana during the summer of 2013.

\begin{tabular}{|c|c|c|c|c|c|c|c|c|c|c|c|c|c|c|c|c|}
\hline \multirow[b]{2}{*}{ Explanatory } & \multirow[b]{2}{*}{ df } & \multicolumn{3}{|l|}{ Mass (g) } & \multicolumn{3}{|l|}{$\mathrm{SVL}(\mathrm{mm})$} & \multicolumn{3}{|c|}{ Total length (mm) } & \multicolumn{3}{|c|}{ Tail length (mm) } & \multicolumn{3}{|c|}{ Tail depth (mm) } \\
\hline & & Estimate & $t$ & $P$ & Estimate & $t$ & $P$ & Estimate & $t$ & $P$ & Estimate & $t$ & $P$ & Estimate & $t$ & $P$ \\
\hline Trout & 3 & 0.34 & 0.97 & 2 & 4.10 & 1.02 & 2 & 8.09 & 1.16 & & 3.84 & 1.05 & & 0.64 & 0.73 & 0.518 \\
\hline Date & 1271 & 0.03 & 8.56 & $<0.001$ & 0.37 & 11.19 & $<0.001$ & 0.69 & 10.33 & $<0.001$ & 0.31 & 7.73 & $<0.001$ & 0.07 & 18.23 & $<0.001$ \\
\hline Trout $\times$ date & 1271 & -0.02 & -3.42 & $<0.001$ & -0.19 & -3.35 & $<0.001$ & -0.39 & -3.79 & $<0.001$ & -0.18 & -2.87 & 0.004 & -0.05 & -13.15 & $<0.001$ \\
\hline Structure $\times$ date & 1271 & -0.00 & -2.08 & 0.037 & -0.04 & -2.34 & 0.020 & -0.58 & -2.08 & 0.038 & - & - & - & -0.01 & -3.31 & 0.001 \\
\hline
\end{tabular}

Note: We removed interactions that did not explain sufficient variation. The variability in degrees of freedom (df) is a function of accounting for the nested study design. SVL, snout-vent length.

Table 2. Factors affecting body morphology of Long-toed Salamanders (Ambystoma macrodactylum) at metamorphosis in experimental enclosures without trout cues or structure ( $n=19$ salamanders, 6 enclosures), without trout cues but with added structure ( $n=24$ salamanders, 6 enclosures), with trout cues but without structure ( $n=52$ salamanders, 8 enclosures), and with trout cues and added structure ( $n=35$ salamanders, 8 enclosures), after accounting for time, in northwestern Montana during the summer of 2013.

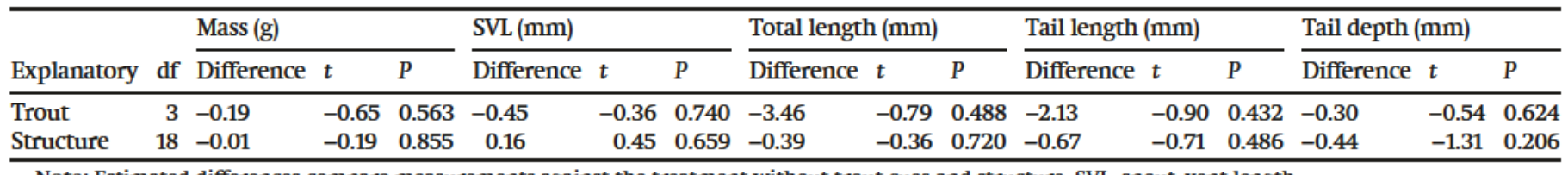

Note: Estimated differences compare measurements against the treatment without trout cues and structure. SVL, snout-vent length.

Fig. 4. Probability of metamorphosis over time for Long-toed Salamanders (Ambystoma macrodactylum) in enclosures without trout cues or added structure (- trout, - structure; $n=19$ of 120 salamanders), without trout cues but with added structure (- trout, + structure; $n=24$ of 123 salamanders), with trout cues but without added structure (+ trout, - structure; $n=36$ of 160 salamanders), and with trout cues and added structure (+ trout, + structure; $n=47$ of 160 salamanders) in northwestern Montana. Day 0 is 30 June and day 43 is 12 August during the summer of 2013.

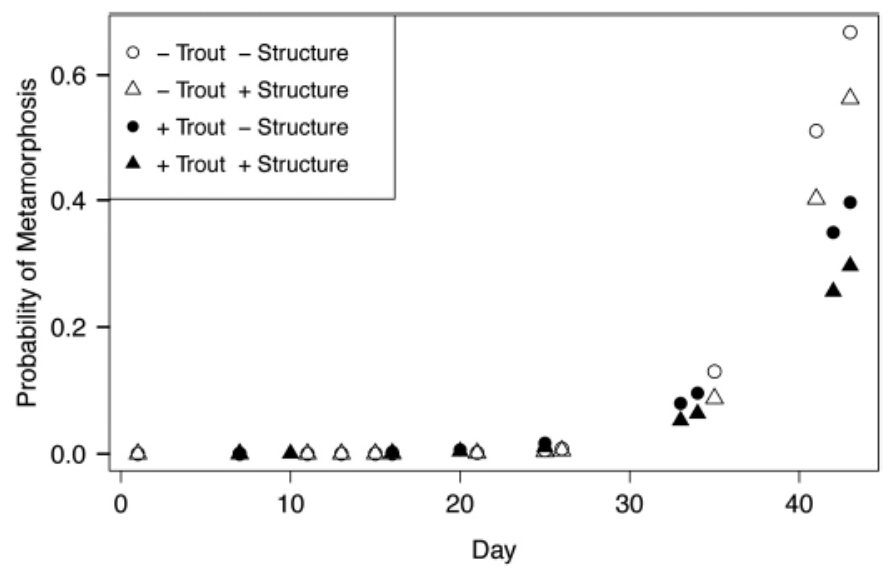

the importance of refugia as protection from predators and the potential role in promoting coexistence between aquatic predators and prey in lentic systems. These findings are congruent with previous studies which found that species richness and occupancy of amphibians within lakes with predatory fish are positively correlated with emergent vegetation (Hecnar and M'Closkey 1997; Hartel et al. 2007). A study of 1749 water bodies in the northern Rocky Mountains found that Long-toed Salamanders only coexisted with trout in $47(2.7 \%)$ lakes, yet $77 \%$ of the lakes with coexisting trout and salamanders contained highly vegetated shallows (76\%-100\% cover; Pilliod et al. 2013). In experiments with freeswimming predators, survival of larval amphibians increases in areas with higher cover and density of plants (Babbitt and Tanner 1997; Baber and Babbitt 2004). The use of refugia by prey can reduce a predator's ability to detect and capture prey, increasing the potential for predator-prey coexistence (Murdoch and Oaten 1975; Diehl 1992; Bartholomew et al. 2000).

Larval amphibians that are capable of detecting the physical presence or chemical cues of predators often increase refuge use to avoid predation (Petranka et al. 1987; Kats et al. 1988; Davenport et al. 2014). For example, tadpoles subjected to a caged predator or fish chemical cues may reduce the time spent foraging by as much as $41 \%$ and reduce the time spent outside of refugia by $68 \%$ (Petranka et al. 1987; Skelly and Werner 1990). Although refuge use reduces the risk of consumption, prey can incur NCEs due to changes in foraging, allocating resources to alter morphology and produce chemical defenses, or both (Brönmark and Miner 1992; Hagman et al. 2009). Long-toed Salamanders that co-occur in lakes with trout weigh $38 \%$ less and are $24 \%$ shorter compared with salamanders in lakes without fish predators (Kenison et al. 2016). Persisting in environments with fish that are perceived to be high risk also increases stress, which can inhibit food intake, suppress appetite, and further contribute to NCEs (Crespi and Denver 2005). Our study demonstrates that salamanders are able to appropriately detect predators and employ avoidance behaviors, but face a trade-off between foraging and safety, given that salamanders exposed to trout cues in our experimental enclosures exhibited slower growth rates and delayed metamorphosis.

Salamanders must reach a minimum body size before metamorphosis can begin (Wilbur and Collins 1973; Nicieza 2000; Babbitt 2001; Altwegg 2002; Benard 2004). We found the probability of metamorphosis was lower in enclosures with trout cues, which suggests that salamanders decrease activity in the presence of predators, reduce growth rates, and subsequently, extend larval periods to reach necessary size thresholds. This finding is congruent with studies of other amphibian species: Southern Leopard Frogs (Lithobates sphenocephalus (Cope, 1886)), Wood Frogs (Lithobates sylvaticus (LeConte, 1825)), and Water Frogs (Pelophylax ridibundus (Pallas, 1771)) extend their larval period when exposed to insect predators, but metamorphose at similar sizes (Babbitt 2001; Relyea 2001; Van Buskirk and Saxer 2001). Similarly, Long-toed Salamanders have reduced growth rates and prolonged larval periods in the presence of cannibalistic conspecifics, but are similar in size at metamorphosis (Wildy et al. 1999). Although uncom- 
mon, some species are able to metamorphose early when subjected to increased risk of predation. For example, Western Toads (Anaxyrus boreas (Baird and Girard, 1852); formerly Bufo boreas Baird and Girard, 1852) decrease time to metamorphosis by $\sim 10$ days when exposed to predatory cues of backswimmers (species of the genus Notonecta L., 1758; Chivers et al. 1999; Relyea 2007).

Fish introductions have been associated with reduced populations of macroinvertebrates, zooplankton, and subsequently, amphibians (Knapp et al. 2001). Given that trout and larval salamanders have overlapping diets, changes in food availability in lakes with trout may have influenced salamander growth and size. However, resource competition is inherently related to nonconsumptive effects of trout. Although we do not have data on fish densities or resource availability for our study lakes, we present strong evidence for a change in growth and probability of metamorphosis as a function of trout cues. Salamanders in enclosures were protected from potential consumptive effects of trout predators, yet they still demonstrated changes in growth and life history. We argue that changes incurred by salamanders, regardless of the exact mechanism (e.g., altered foraging behavior or resource competition), still provide evidence of nonconsumptive effects of trout.

Salamanders that extend their larval period in lakes with trout may increase their exposure to predators and risk of mortality, thus reducing the number of individuals that leave the pond to successfully enter the terrestrial system as adults. Although we did not find evidence that adding vegetation structure helped to mitigate NCEs of trout, Orizaola and Braña (2003) found that more abundant available refugia increased survival of larval newts more than two-fold in the presence of fish predators. We found that salamanders in lakes with trout used more densely vegetated areas; we captured salamanders more often in open water in lakes without trout. Dense vegetation may increase survival in the presence of trout, but may also provide less-than-ideal foraging areas for salamanders. In the presence of piscivorous largemouth bass (Micropterus salmoides (Lacepède, 1802)), small bluegills (Lepomis macrochirus Rafinesque, 1819) survive by foraging in protected vegetated habitat, but only acquire one-third of the resources found in open water (Werner et al. 1983). Habitat features such as rocks, woody material, vegetation, and small interstitial spaces provide effective protection from fish predators and also are associated with increased density and species richness of invertebrates (Stenhouse 1985; Babbitt and Jordan 1996; Hartel et al. 2007). Our experimental vegetation structures may have been too small to reduce the perceived risk of predation and may not have been in place long enough to provide sufficient food resources for larval salamanders. Therefore, by adding larger, more diverse structures to lakes and allowing time for invertebrate prey to establish, we might be able to create highly productive, food-rich areas, where salamanders can forage efficiently and safely from trout.

Complete removal of fish from mountain lakes has been successful in increasing population sizes of amphibians (Knapp et al. 2007). However, future research focused on adding complex structure at a whole-lake scale will be important to understand whether this strategy can be effective at reducing the consumptive and nonconsumptive effects of trout while preserving recreational fishing opportunities. Previous conservation projects for amphibians have been limited to maintaining buffer zones around breeding sites, creating connectivity between wetlands, or constructing new and restoring anthropogenically altered water bodies (Semlitsch 2002; Shulse et al. 2012). If adding vegetation structure at larger scales can increase resource availability for larval salamanders, then this management strategy may be the most feasible to mitigate NCEs of nonnative trout without requiring the removal of fish.

\section{Acknowledgements}

This work was funded by Montana State University, with additional financial support from Montana Fish, Wildlife and Parks, Counter Assault, and Montana Institute on Ecosystems. We are grateful to M. Forzley for his work as a field technician, B. Tornabene for his statistical assistance, and reviewers for their constructive comments. Any use of trade, product, or firm names is for descriptive purposes only and does not imply endorsement by the U.S. Government.

\section{References}

Adams, M.J., Richter, K.O., and Leonard, W.P. 1997. Surveying and monitoring amphibians using aquatic funnel traps. Northwest Fauna, 4: 47-54.

Altwegg, R. 2002. Predator-induced life-history plasticity under time constraints in pool frogs. Ecology, 83(9): 2542-2551. doi:10.1890/0012-9658(2002)083[2542: PILHPU]2.0.CO;2.

Amtzen, J. 1981. Ecological observations on Chioglossa lusitanica (Caudate, Salamandridae). Amphib.-Reptilia, 1(3-4): 187-204. doi:10.1163/156853881X00311.

Babbitt, K.J. 2001. Behaviour and growth of southern leopard frog (Rana sphenocephala) tadpoles: effects of food and predation risk. Can. J. Zool. 79(5): 809-814. doi:10.1139/z01-040.

Babbitt, K.J., and Jordan, F. 1996. Predation on Bufo terrestris tadpoles: effects of cover and predator identity. Copeia, 1996(2): 485-488. doi:10.2307/1446873.

Babbitt, K.J., and Tanner, G.W. 1997. Effects of cover and predator identity on predation of Hyla squirella tadpoles. J. Herpetol. 31(1): 128-130. doi:10.2307| 1565342.

Baber, M.J., and Babbitt, K.J. 2004. Influence of habitat complexity on predatorprey interactions between the fish (Gambusia holbrooki) and tadpoles of Hyla squirella and Gastrophryne carolinensis. Copeia, 2004(1): 173-177. doi:10.1643/CE03-056R1.

Bartholomew, A., Diaz, R.J., and Cicchetti, G. 2000. New dimensionless indices of structural habitat complexity: predicted and actual effects on a predator's foraging success. Mar. Ecol. Prog. Ser. 206: 45-58. doi:10.3354/meps206045.

Benard, M.F. 2004. Predator-induced phenotypic plasticity in organisms with complex life histories. Annu. Rev. Ecol. Evol. Syst. 35(1): 651-673. doi:10.1146| annurev.ecolsys.35.021004.112426.

Brönmark, C., and Miner, J.G. 1992. Predator-induced phenotypical change in body morphology in crucian carp. Science, 258(5086): 1348-1350. doi:10.1126| science.258.5086.1348. PMID:17778362.

Bull, E.L., and Marx, D.B. 2002. Influence of fish and habitat on amphibian communities in high elevation lakes in northeastern Oregon. Northwest Sci. 76(3): 240-248.

Chivers, D.P., Kiesecker, J.M., Marco, A., Wildy, E.L., and Blaustein, A.R. 1999. Shifts in life history as a response to predation in western toads (Bufo boreas). J. Chem. Ecol. 25(11): 2455-2463. doi:10.1023/A:1020818006898.

Clark, K.L. 1986. Responses of spotted salamander, Ambystoma maculatum, populations in central Ontario to habitat acidity. Can. Field-Nat. 100(4): 463-469.

Crawford, S.S., and Muir, A.M. 2008. Global introductions of salmon and trout in the genus Oncorhynchus: 1870-2007. Rev. Fish Biol. Fishes, 18: 313-344. doi:10. 1007/s11160-007-9079-1.

Crespi, E.J., and Denver, R.J. 2005. Roles of stress hormones in food intake regulation in anuran amphibians throughout the life cycle. Comp. Biochem. Physiol. Part A Mol. Integr. Physiol. 141(2005): 381-390. doi:10.1016/j.cbpb. 2004.12.007.

Crowder, L.B., and Cooper, W.E. 1982. Habitat structural complexity and the interaction between bluegills and their prey. Ecology, 63(6): 1802-1813. doi: $10.2307 / 1940122$.

Cucherousset, J., and Olden, J.D. 2011. Ecological impacts of nonnative freshwater fishes. Fisheries (Bethesda), 36(5): 215-230. doi:10.1080/03632415.2011. 574578.

Davenport, J.M., Hossack, B.R., and Lowe, W.H. 2014. Partitioning the nonconsumptive effects of predators on prey with complex life histories. Oecologia, 176: 149-155. doi:10.1007/s00442-014-2996-5. PMID:24965938.

Diehl, S. 1992. Fish predation and benthic community structure: the role of omnivory and habitat complexity. Ecology, 73(5): 1646-1661. doi:10.2307| 1940017.

Dodd, M.H.I., and Dodd, J.M. 1976. The biology of metamorphosis. In Physiology of the Amphibia. Edited by B. Lofts. Academic Press, New York. pp. 467-599.

Duellman, W.E., and Trueb, L. 1986. Biology of amphibians. McGraw-Hill, New York.

Dunham, J.B., Pilliod, D.S., and Young, M.K. 2004. Assessing the consequences of nonnative trout in headwater ecosystems in western North America. Fisheries (Bethesda), 29(6): 18-26. doi:10.1577/1548-8446(2004)29[18:ATCONT]2.0.CO;2.

Figiel, C.R., Jr., and Semlitsch, R.D. 1990. Population variation in survival and metamorphosis of larval salamanders (Ambystoma maculatum) in the presence and absence of fish predation. Copeia, 1990(3): 818-826. doi:10.2307/1446447.

Funk, W.C., and Dunlap, W.W. 1999. Colonization of high-elevation lakes by long-toed salamanders (Ambystoma macrodactylum) after the extinction of introduced trout populations. Can. J. Zool. 77(11): 1759-1767. doi:10.1139/z99-160. 
Hagman, M., Hayes, R.A., Capon, R.J., and Shine, R. 2009. Alarm cues experienced by cane toad tadpoles affect post-metamorphic morphology and chemical defences. Funct. Ecol. 23: 126-132. doi:10.1111/j.1365-2435.2008.01470.x.

Hartel, T., Nemes, S., Cogånniceanu, D., Öllerer, K., Schweiger, O., Moga, C., and Demeter, L. 2007. The effect of fish and aquatic habitat complexity on amphibians. Hydrobiologia, 583: 173-182. doi:10.1007/s10750-006-0490-8.

Hecnar, S.J., and M'Closkey, R.T. 1997. The effects of predatory fish on amphibian species richness and distribution. Biol. Conserv. 79: 123-131. doi:10.1016/S00063207(96)00113-9.

Himer, J.L.M., and Cox, S.P. 2007. Effects of rainbow trout (Oncorhynchus mykiss) on amphibians in productive recreational fishing lakes of British Columbia. Can. J. Fish. Aquat. Sci. 64(12): 1770-1780. doi:10.1139/f07-139.

Kats, L.B., and Ferrer, R.P. 2003. Alien predators and amphibian declines: review of two decades of science and the transition to conservation. Divers. Distrib. 9: 99-110. doi:10.1046/j.1472-4642.2003.00013.x.

Kats, L.B., Petranka, J.W., and Sih, A. 1988. Antipredator defenses and the persistence of amphibian larvae with fishes. Ecology, 69(6): 1865-1870. doi:10. $2307 / 1941163$.

Kenison, E.K., Litt, A.R., Pilliod, D.S., and McMahon, T. 2016. Larval long-toed salamanders incur nonconsumptive effects in the presence of nonnative trout. Ecosphere. [In press.]

Kiesecker, J.M., and Blaustein, A.R. 1998. Effects of introduced bullfrogs and smallmouth bass on microhabitat use, growth, and survival of native redlegged frogs (Rana aurora). Conserv. Biol. 12(4): 776-787. doi:10.1046/j.15231739.1998.97125.x

Kinsolving, A.D., and Bain, M.B. 1990. A new approach for measuring cover in fish habitat studies. J. Freshw. Ecol. 5(3): 373-378. doi:10.1080/02705060.1990. 9665250.

Knapp, R.A., Matthews, K.R., and Sarnelle, O. 2001. Resistance and resilience of alpine lake fauna to fish introductions. Ecol. Monogr. 71: 401-421. doi:10.1890/ 0012-9615(2001)071[0401:RAROAL]2.0.CO;2.

Knapp, R.A., Boiano, D.M., and Vredenburg, V.T. 2007. Removal of nonnative fish results in population expansion of a declining amphibian (mountain yellowlegged frog, Rana muscosa). Biol. Conserv. 135:11-20. doi:10.1016/j.biocon.2006. 09.013. PMID:17396156.

McNair, J.N. 1986. The effects of refuges on predator-prey interactions: a reconsideration. Theor. Popul. Biol. 29: 38-63. doi:10.1016/0040-5809(86)90004-3. PMID:3961711.

Murdoch, W.W., and Oaten, A. 1975. Predation and population stability. Adv. Ecol. Res. 9: 1-129. doi:10.1016/S0065-2504(08)60288-3.

Nicieza, A.G. 2000. Interacting effects of predation risk and food availability on larval anuran behaviour and development. Oecologia, 123: 497-505. doi:10. $1007 / \mathrm{s} 004420000343$.

O'Connor, N.A. 1991. The effects of habitat complexity on the macroinvertebrates colonizing wood substrates in a lowland stream. Oecologia, 85: 504512. doi:10.1007/BF00323762.

Orizaola, G., and Braña, F. 2003. Response of predator-naïve newt larvae to food and predator presence. Can. J. Zool. 81(11): 1845-1850. doi:10.1139/z03-160.

Pearson, K.J., and Goater, C.P. 2008. Distribution of long-toed salamanders and introduced trout in high- and low-elevation wetlands in southwestern $\mathrm{Al}$ berta, Canada. Ecoscience, 15: 453-459. doi:10.2980/15-4-3127.

Pearson, K.J., and Goater, C.P. 2009. Effects of predaceous and nonpredaceous introduced fish on the survival, growth, and antipredation behaviours of long-toed salamanders. Can. J. Zool. 87(10): 948-955. doi:10.1139/Z09-084.

Petranka, J.W., Kats, L.B., and Sih, A. 1987. Predator-prey interactions among fish and larval amphibians: use of chemical cues to detect predatory fish. Anim. Behav. 35: 420-425. doi:10.1016/S0003-3472(87)80266-X.

Pilliod, D.S., and Peterson, C.R. 2001. Local and landscape effects of introduced trout on amphibians in historically fishless watersheds. Ecosystems, 4: 322333. doi:10.1007/s10021-001-0014-3.

Pilliod, D.S., Hossack, B.R., Bahls, P.F., Bull, E.L., Corn, P.S., Hokit, G., Maxell, B.A., Munger, J.C., and Wyrick, A. 2010. Non-native salmonids affect amphibian occupancy at multiple spatial scales. Divers. Distrib. 16: 959-974. doi:10.1111/j.1472-4642.2010.00699.x.

Pilliod, D.S., Griffiths, R.A., and Kuzmin, S.L. 2012. Ecological impacts of nonnative species. In Conservation and decline of amphibians: ecological aspects, effect of humans, and management. Vol. 10. Edited by $\mathrm{H}$. Heatwole and J.W. Wilkinson. Surrey Beatty and Sons, NSW, Australia. pp. 3343-3382.

Pilliod, D.S., Arkle, R.S., and Maxell, B.A. 2013. Persistence and extirpation in invaded landscapes: patch characteristics and connectivity determine effects of non-native predatory fish on native salamanders. Biol. Invasions, 15: 671685. doi:10.1007/s10530-012-0317-7.

R Core Team. 2013. R: a language and environment for statistical computing. R Foundation for Statistical Computing, Vienna, Austria. Available from https://www.r-project.org/.

Relyea, R.A. 2001. Morphological and behavioral plasticity of larval anurans in response to different predators. Ecology, 82(2): 523-540. doi:10.1890/00129658(2001)082[0523:MABPOL]2.0.CO;2.

Relyea, R.A. 2007. Getting out alive: how predators affect the decision to metamorphose. Oecologia, 152(3): 389-400. doi:10.1007/s00442-007-0675-5. PMID: 17356812.

Rosenzweig, M.L., and MacArthur, R.H. 1963. Graphical representation and stability conditions of predator-prey interactions. Am. Nat. 97(895): 209-223. doi:10.1086/282272.

Schneider, K.N., and Winemiller, K.O. 2008. Structural complexity of woody debris patches influences fish and macroinvertebrate species richness in a temperate floodplain-river system. Hydrobiologia, 610: 235-244. doi:10.1007| s10750-008-9438-5.

Semlitsch, R.D. 1987. Interactions between fish and salamander larvae. Costs of predator avoidance or competition? Oecologia, 72(4): 481-486. doi:10.1007| BF00378972.

Semlitsch, R.D. 2002. Critical elements for biologically based recovery plans of aquatic-breeding amphibians. Conserv. Biol. 16(3): 619-629. doi:10.1046/j.15231739.2002.00512.x.

Shulse, C.D., Semlitsch, R.D., Trauth, K.M., and Gardner, J.E. 2012. Testing wetland features to increase amphibian reproductive success and species richness for mitigation and restoration. Ecol. Appl. 22(5): 1675-1688. doi:10.1890/ 11-0212.1. PMID:22908722.

Sih, A. 1987. Prey refuges and predator-prey stability. Theor. Popul. Biol. 31: 1-12. doi:10.1016/0040-5809(87)90019-0.

Sih, A., Petranka, J.W., and Kats, L.B. 1988. The dynamics of prey refuge use: a model and tests with sunfish and salamander larvae. Am. Nat. 132(4): 463483. doi:10.1086/284865.

Skelly, D.K., and Werner, E.E. 1990. Behavioral and life-historical responses of larval American toads to an odonate predator. Ecology, 71(6): 2313-2322. doi: $10.2307 / 1938642$.

Sredl, M.J., and Collins, J.P. 1991. The effect of ontogeny on interspecific interactions in larval amphibians. Ecology, 72(6): 2232-2239. doi:10.2307/1941573.

Stenhouse, S.L. 1985. Interdemic variation in predation on salamander larvae. Ecology, 66(6): 1706-1717. doi:10.2307/2937366.

Tarr, T.L., and Babbitt, K.J. 2002. Effects of habitat complexity and predator identity on predation of Rana clamitans larvae. Amphib.-Reptilia, 23: 13-20. doi:10.1163/156853802320877591.

Tyler, T., Liss, W.J., Ganio, L.M., Larson, G.L., Hoffman, R., Deimling, E., and Lomnicky, G. 1998a. Interaction between introduced trout and larval salamanders (Ambystoma macrodactylum) in high-elevation lakes. Conserv. Biol. 12(1): 94-105. doi:10.1046/j.1523-1739.1998.96274.x.

Tyler, T.J., Liss, W.J., Hoffman, R.L., and Ganio, L.M. 1998b. Experimental analysis of trout effects on survival, growth, and habitat use of two species of ambystomatid salamanders. J. Herpetol. 32(3): 345-349. doi:10.2307/1565448.

Van Buskirk, J., and Saxer, G. 2001. Delayed costs of an induced defense in tadpoles? Morphology, hopping, and development rate at metamorphosis. Evolution, 55(4): 821-829. doi:10.1111/j.0014-3812.2001.tb00817.x.

Welsh, H.H., Pope, K.L., and Boiano, D. 2006. Sub-alpine amphibian distributions related to species palatability to non-native salmonids in the Klamath mountains of northern California. Divers. Distrib. 12(3): 298-309. doi:10.1111/j.13669516.2006.00254.x.

Werner, E.E., Gilliam, J.F., Hall, D.J., and Mittelbach, G.G. 1983. An experimental test of the effects of predation risk on habitat use in fish. Ecology, 64(6): 1540-1548. doi:10.2307/1937508.

Wilbur, H.M., and Collins, J.P. 1973. Ecological aspects of amphibian metamorphosis: nonnormal distributions of competitive ability reflect selection for facultative metamorphosis. Science, 182(4119): 1305-1314. doi:10.1126/science. 182.4119.1305. PMID:17733097.

Wildy, E.L., Chivers, D.P., and Blaustein, A.R. 1999. Shifts in life-history traits as a response to cannibalism in larval long-toed salamanders (Ambystoma macrodactylum). J. Chem. Ecol. 25(10): 2337-2346. doi:10.1023/A:1020830125611.

Zuur, A., Ieno, E.N., Walker, N., Saveliev, A.A., and Smith, G.M. 2009. Mixed effects models and extensions in ecology with R. Springer-Verlag, New York. 